\title{
Case Report: Effect of Chelation Therapy on Lead-induced Hepatotoxicity: A Case Series
}

\author{
Faezeh Shadfar $^{1}$ Q , Zakaria Zakariaei ${ }^{2}$, Seyed Khosro Ghasempoori ${ }^{2}$ Q Mahmood Moosazadeh $^{3}$, Navid Khosravi $^{2^{*}}$ \\ 1. Department of Clinical Pharmacy, School of Pharmacy, Mazandaran University of Medical Sciences, Sari, Iran. \\ 2. Department of Emergency Medicine, School of Medicine, Mazandaran University of Medical Sciences, Sari, Iran. \\ 3. Health Sciences Research Center, Mazandaran University of Medical Sciences, Sari, Iran.
}

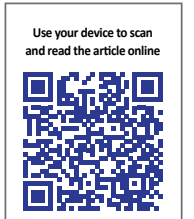

Citation: Shadfar F, Zakariaei Z, Ghasempoori SK, Moosazadeh M, Khosravi N. Effect of Chelation Therapy on Leadinduced Hepatotoxicity: A Case Series. International Journal of Medical Toxicology and Forensic Medicine. 2019; 9(3):159-164. https://doi.org/10.32598/ijmtfm.v9i3.25603

https://doi.org/10.32598/ijmtfm.v9i3.25603

(c) $0(3)$

Article info:

Received: 12 Dec 2018

First Revision: 10 Jan 2019

Accepted: 15 Apr 2019

Published: 01 Jul 2019

\section{Keywords:}

Lead poisoning, Liver failure, Chelation therapy, Liver function tests

\section{ABSTRACT}

Background: Opium use is one of the common causes of lead toxicity. Lead poisoning can lead to hepatic, hematologic, musculoskeletal, neurological, and cardiovascular damages. In this study, we investigated the reversibility of lead-induced liver damage following chelation therapy.

Methods: We reviewed the medical records of patients with opium-induced lead poisoning regarding elevation in hepatobiliary enzymes level including Alanine Transaminase (ALT), Aspartate Transaminase (AST), and Alkaline Phosphatase (ALP) to normal level and recorded patients' age, treatment regimen, liver enzymes level before and after treatment; we also investigated other laboratory findings to rule out other causes of liver enzymes increase.

Results: We evaluated 10 male patients with the mean age of $48.3 \pm 7.42$ years. All patients were referred with the chief complain of abdominal cramps (100\%). The mean lead level in patients was $84.48 \pm 9.95 \mu \mathrm{g} / \mathrm{dL}$. The mean serum levels of ALT, AST, and ALP significantly decreased after the treatment with chelating agents $([\mathrm{ALT}=117.8 \pm 60.22 \mu \mathrm{g} / \mathrm{dL}-76.9 \pm 40.73 \mu \mathrm{g} /$ $\mathrm{dL}, \mathrm{P}=0.022],[\mathrm{AST}=100.9 \pm 63.96 \mu \mathrm{g} / \mathrm{dL}-69.9 \pm 37.41 \mu \mathrm{g} / \mathrm{dL}, \mathrm{P}=0.028],[\mathrm{ALP}=449.8 \pm 234.81$ $\mu \mathrm{g} / \mathrm{dL}-338.3 \pm 131.22 \mu \mathrm{g} / \mathrm{dL}, \mathrm{P}=0.037])$. There was no significant correlation between patients' lead level and liver enzymes level before and after the treatment.

Conclusion: The results of this study showed that the treatment with chelating agents reverses the liver injury following the lead intoxication.

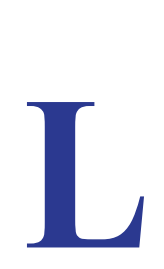

\section{Introduction}

ead is one of the heavy metals with no beneficial nutritional effect [1]; it is found in gasoline, paint substances, leadcontaminated opioids, and industrial, construction, and chemical materials [1-4]. The lead is absorbed by gastrointestinal and respiratory tracts and, subsequently, stores in the bone and soft tissue; about $(33 \%)$ of the soft tissue sources is in the liver. The acceptable level of lead in adults is $40 \mu \mathrm{g} / \mathrm{dL}$ and at higher concentration, the toxicity symptoms will appear $[1,3]$.

* Corresponding Author:

Navid Khosravi, PhD Candidate.

Address: Department of Emergency Medicine, School of Medicine, Mazandaran University of Medical Sciences, Sari, Iran.

Tel: +98 (914) 1453365

E-mail: Khosravi.navid@gmail.com 
The excessive amounts of lead can be replaced with trace elements and harm various tissues and organs [1]. Following the lead poisoning, gastrointestinal symptoms (including abdominal cramps, small intestinal paralysis, and constipation), kidney symptoms (such as increase in urea and creatinine following its accumulation in the cortex and medulla), as well as Central Nervous System (CNS) symptoms (such as encephalopathy) will occur $[1,3]$. However, nephropathy symptoms do not appear rapidly because of the high renal capacity until (50\%) of the nephrons get damaged [1].

The liver is the first organ, which receives and accumulates nutrients, xenobiotics, and medications through a portal vein in order to metabolize them. Lead intoxication has several effects on liver function such as the inhibition of heme synthesis, the reduction of estradiol-17 $\beta$ activity, the inhibition of metabolism through CYP450 enzymes, the reduction of aminopyrine N-demethylase activity, and increase in the activity of phase-II hepatic metabolism; they include glutathione, glutathione stransferase, and Nicotinamide Adenine Dinucleotide Phosphate (NADPH), indicating liver nodules and carcinogenic effects of lead on the liver [3].

Lead accumulation in the liver leads to oxidative stress, increase in the lipid peroxidation, the expression of inflammatory cytokines (including TNF-alpha, the inhibition of antioxidant activity, decrease in the Adenosine Triphosphate [ATP] stores of hepatocytes), and the induction of apoptosis in Kupffer cells [3]. In this study, we plan to investigate the correlation between the lead level and increase in liver biomarkers, as well as the possibility of reversing liver damage following the treatment with chelating agents.

\section{Patients and Methods}

In this retrospective study, the medical records of 10 lead intoxication patients with any raising in the level of liver enzymes more than normal range were investigated between April 2014 and May 2018. The exclusion criteria included the history of other liver diseases. The patients' hepatobiliary enzymes; Alanine Transaminase (ALT), Aspartate Transaminase (AST), and Alkaline Phosphatase (ALP) were recorded at the basal hospitalization time and at the end of chelation therapy. Also, other laboratory markers including Hepatitis A Virus (HAV Ab), Hepatitis B Surface Antigen (HBsAg), Hepatitis B Core Antibody (HbsAb), Hepatitis C Antibody (HCV Ab), Human Immunodeficiency Virus (HIV), MIX, amylase, and lipase were recorded to rule out other diseases that can disrupt liver function tests in- cluding hepatitis A, B, C, HIV, and pancreatitis. Also, the patient's troponin-I level was investigated to rule out the cardiac source of AST increase.

\section{Statistical analysis}

Quantitative variables are represented as Mean \pm SD and qualitative variables as a percentage. In order to compare hepatic enzymes level changes before and after the treatment, the Wilcoxon test was performed. The Mann-Whitney test was used to determine the correlation between the enzymes level and treatment regimens. All statistical analyses were conducted by SPSS V. 24 (SPSS Inc., Chicago, IL, USA). P value $<0.05$ were considered significant.

\section{Results}

Ten patients with lead poisoning and impaired liver function were enrolled in the study. The mean age of the patients was $48.3 \pm 7.42$ years. Patients experienced gastrointestinal symptoms including abdominal cramps (100\%), constipation (30\%), nausea and vomiting (20\%), anorexia (10\%), diarrhea (10\%), as well as a neurologic symptom (seizure) (10\%). None of the patients showed evidence of hepatitis A, B, C, and HIV-associated antigens or antibodies. Also, no increase was observed in troponin-I level as a marker of cardiovascular events, which impacted the AST level (Table 1). The peripheral blood sample of all patients showed the evidence of basophilic stippling, which confirmed the lead toxicity.

In the current study, the mean lead level of the patients was $84.48 \pm 9.95 \mu \mathrm{g} / \mathrm{dL}$ (range between 68.9 and $99.8 \mu \mathrm{g}$ / $\mathrm{dL}$ ). The mean level of ALT, AST, and ALP significantly decreased after treatment ([ALT $=117.8 \pm 60.22 \mu \mathrm{g} / \mathrm{dL}$ $76.9 \pm 40.73 \mu \mathrm{g} / \mathrm{dL}, \mathrm{P}=0.022],[\mathrm{AST}=100.9 \pm 63.96 \mu \mathrm{g} / \mathrm{dL}-$ $69.9 \pm 37.41 \mu \mathrm{g} / \mathrm{dL}, \quad \mathrm{P}=0.028], \quad[\mathrm{ALP}=449.8 \pm 234.81 \mu \mathrm{g} /$ $\mathrm{dL}-338.3 \pm 131.22 \mu \mathrm{g} / \mathrm{dL}, \mathrm{P}=0.037])$. There was no significant correlation between the lead and enzymes level at the baseline (before the treatment) or after the treatment $(\mathrm{P}>0.05)$. Also, there was no significant correlation between the patients' age and level of liver enzymes release after lead poisoning, as well as their reduction after treatment $(\mathrm{P}>0.05)$.

\section{Discussion}

In recent years, occupational-associated lead poisoning has shown a dramatic reduction in industrialized societies and many other countries. Opioid-associated toxicity is considered the main cause of lead poisoning in our country in comparison with occupational causes 


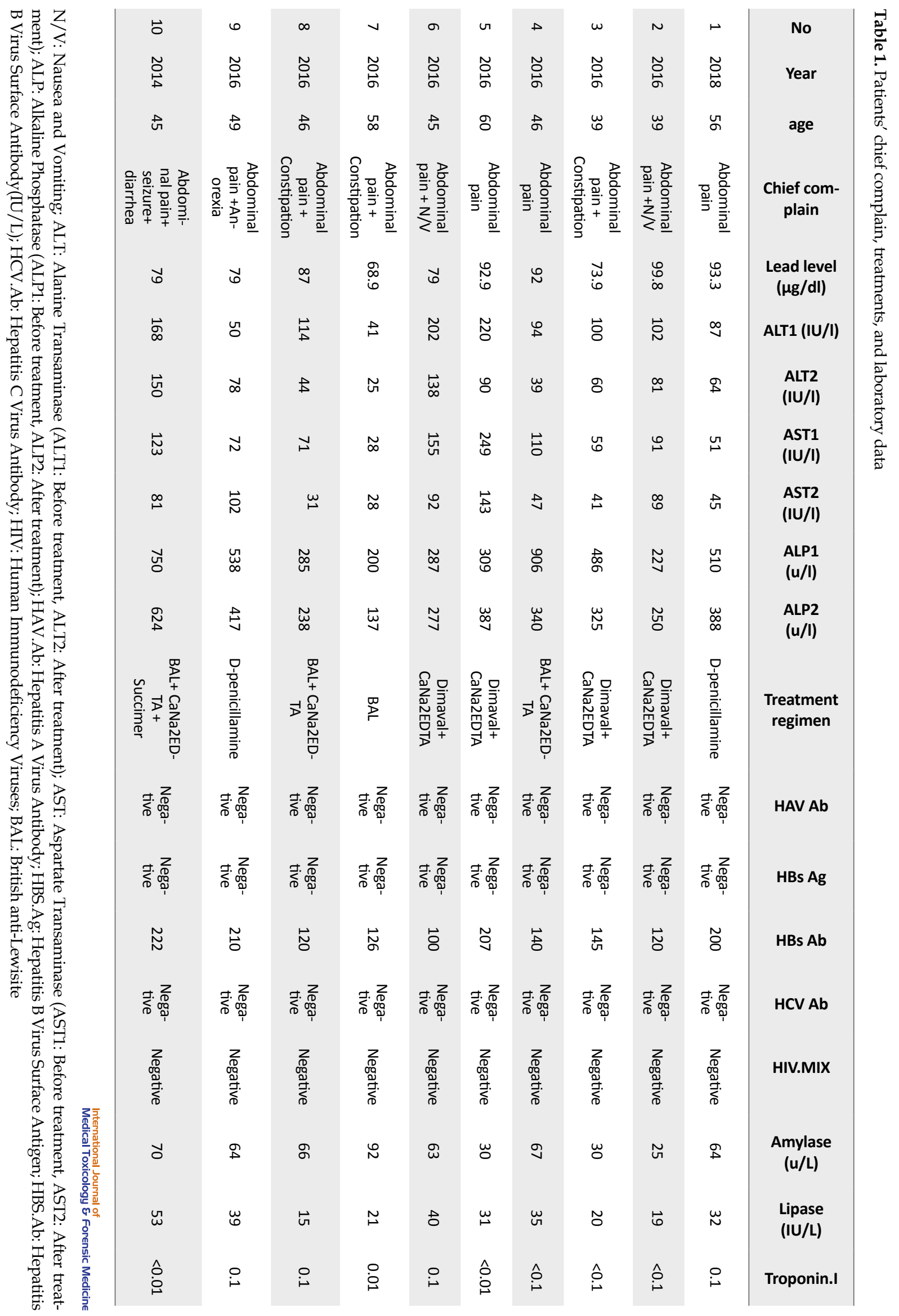


[5]. Lead poisoning disrupts cardiovascular, hematopoietic, neurological, and renal function [2, 4-7]. Acute lead poisoning requires exposure to higher concentrations of lead compared to chronic poisoning (100-200 $\mu \mathrm{g} / \mathrm{dL}$ vs. 40-60 $\mu \mathrm{g} / \mathrm{dL}$ ) [8]. The acute symptoms of lead poisoning commonly include gastrointestinal signs and symptoms such as abdominal colic, back pain, nausea, vomiting, anorexia, and constipation. Lead toxicity is one of acute abdominal pain differential diagnosis [2, 5]. The lack of gastrointestinal symptoms can reduce the doubt of the medical team regarding the lead poisoning; in the current report, all of 10 patients were referred with gastrointestinal complications. The other symptoms of acute intoxication include muscular symptoms such as fatigue, weakness and pain, and neurological symptoms like headache, irritability, sleep disorders, neuropathy, seizure, and coma. In chronic exposure, which presents in low-concentration exposure in the long term, clinical symptoms such as persistent vomiting, encephalopathy, and coma may appear $[5,8]$.

Subacute toxicity may lead to changes in the morphology and function of hepatocytes, bile pigmentation disorders, hemosiderosis of Kupffer cells, hepatitis, and even necrosis of liver cells. It induces cellular growth factors function including TGF $\alpha 1$ and TGF $\beta$, causes cellular proliferation and hyperplasia, and leads to the development of neoplasia [3]. Also, high lead level induces oxidative stress in red blood cells, distributes heme synthesis cycle, the production of abnormal erythrocytes, the deposition of iron in endoplasmic reticulum system and the decrease in the iron-binding capacity [2].

The lead induces lipid peroxidation and depletion of glutathione deposits, especially in Kupffer cells, and disrupts hepatocytes functions, membrane transportation, and cellular metabolism. Lead enters the liver through binding to plasma proteins and disrupts the function of the enzyme involved in the DNA, RNA, and proteins synthesis. It interrupts the liver protein synthesis such as albumin and increases the serum level of some enzymes such as ALT, AST, ALP, and lactate dehydrogenase [3, 6, 9]. A study shows that the elevation of ALP and lactate dehydrogenase occurred at a lead level above $78 \mu \mathrm{g} / \mathrm{dL}$, but not in lower concentrations [3].

As in our study, the patients with higher lead level showed a higher level of enzymes release after intoxication (Table 1). One study demonstrates that lead causes a dose-dependent increase in ALT level in patients with no evidence of hemochromatosis, viral hepatitis, or alcoholic hepatic injury [10]. However, there was no correlation between lead concentration and hepatobiliary en- zymes level before or after the treatment in our patients $(\mathrm{P}>0.05)$. Chang et al. introduced ALT and Gamma-Glutamyl Transferase (GGT) as hepatic injury biomarkers before irreversible changes [10]. Sreeram et al. also explained that GGT is a marker for the evaluation of liver oxidative stress [11]. However, in our study, this maker was only examined in 1 patient, showing an upward trend (patient N-10, GGT [before treatment] $=89 \mathrm{U} / \mathrm{L}$ ).

The treatment of lead toxicity is based on chelating agents including Succimer, Dimercaprol British AntiLewisite (BAL), DMSA, CaNa2EDTA, and D-penicillamine. However, BAL is not recommended to be used alone because of its ability to cross from the blood-brain barrier, the possibility of redistribution, and unpleasant effects such as nausea, vomiting, fever, hypertension, and tachycardia. Many experts recommend combination therapy of BAL and CaNa2EDTA, especially in severe cases $[12,13]$. In our study, 1 patient received only BAL because of the unavailability of Succimer or CaNa2EDTA.

The results of this study indicate that the treatment with chelating agents reduces the liver enzymes level and restores liver damage following lead poisoning so that the levels of liver enzymes significantly decreased in these patients after treatment $(\mathrm{P}<0.05)$. Only one of the penicillamine-treated patients experienced a slight increase in ALT and AST level. Wollheim and Lindstrom in their study stated that penicillamine can increase ALT, AST, ALP, and lactate dehydrogenase level, which can reverse with its discontinuation. However, they reported evidence of histological and inflammatory changes [14].

\section{Conclusion}

Overall, in this study, we observed that the treatment with chelating agents significantly decreased the levels of hepatobiliary enzymes in patients with opium associated-lead poisoning. However, subsequent histological studies are also needed to investigate the effects of these treatments on the long-term changes of liver tissue.

\section{Ethical Considerations}

\section{Compliance with ethical guidelines}

There was no ethical considerations to be considered in this research. 


\section{Funding}

This research did not receive any specific grant from funding agencies in the public, commercial, or not-forprofit sectors.

\section{Author's contributions}

Statistical analysis of data: Mahmood Moosazadeh; Data collection and preparation of the manuscript: Faeze Shadfar, Zakaria Zakariaei, Seyed Khosro Ghasempoori, Mahmood Moosazadeh, Navid Khosravi.

\section{Conflict of interest}

The authors declared no conflict of interest.

\section{Acknowledgements}

The authors would like to sincerely thank the staff of the toxicology unit of Razi Hospital for their supports in data collection.
[8] Flora G, Gupta D, Tiwari A. Toxicity of lead: A review with recent updates. Interdisciplinary Toxicology. 2012; 5(2):47-58 [DOI:10.2478/v10102-012-0009-2]

[9] Bashandy S. Beneficial effect of combined administration of vitamin $\mathrm{C}$ and vitamin $\mathrm{E}$ in amelioration of chronic lead hepatotoxicity. Egyptian Journal Of Hospital Medicine. 2006; 23:371-84.

[10] Chang W-J, Joe K-T, Park H-Y, Jeong J-D, Lee D-H. The relationship of liver function tests to mixed exposure to lead and organic solvents. Annals of Occupational and Environmental Medicine. 2013; 25(1):5. [DOI:10.1186/2052-4374-25-5]

[11] Sreeram M, Suryakar AN, Dani NH. Is gamma-glutamyl transpeptidase a biomarker for oxidative stress in periodontitis? Journal of Indian Society of Periodontology. 2015; 19(2):150. [DOI:10.4103/0972-124X.149032]

[12] Thuppil V, Tannir S. Treating lead toxicity: Possibilities beyond synthetic chelation. The Journal of Krishna Institute of Medical Sciences University. 2013; 2(1):4-31

[13] Aaseth J, Ajsuvakova OP, Skalny AV, Skalnaya MG, Tinkov AA. Chelator combination as therapeutic strategy in mercury and lead poisonings. Coordination Chemistry Reviews. 2018; 358:1-12. [DOI:10.1016/j.ccr.2017.12.011]

[14] Wollheim FA, Lindström CG. Liver abnormalities in penicillamine treated rheumatoid arthritis. Scandinavian Journal of Rheumatology. 1979; 8(suppl. 28):100-5. [DOI:10.3109/03009747909108248]

\section{References}

[1] Dioka C, Orisakwe O, Adeniyi F, Meludu S. Liver and renal function tests in artisans occupationally exposed to lead in mechanic village in Nnewi, Nigeria. International Journal of Environmental Research and Public Health. 2004; 1(1):21-5. [DOI:10.3390/ijerph2004010021]

[2] Verheij J, Voortman J, van Nieuwkerk C, Jarbandhan S, Mulder C, Bloemena E. Hepatic morphopathologic findings of lead poisoning in a drug addict: A case report. Journal of Gastrointestinal and Liver Diseases. 2009; 18(2):225-7.

[3] Mudipalli A. Lead hepatotoxicity \& potential health effects. Indian Journal of Medical Research. 2007; 126(6):518-28. [PMID]

[4] KianoushS, Balali $\square$ Mood M, MousaviSR, Moradi V, Sadeghi M, Dadpour B, et al. Comparison of therapeutic effects of garlic and $\mathrm{d} \square$ Penicillamine in patients with chronic occupational lead poisoning. Basic \& clinical Pharmacology \& Toxicology. 2012; 110(5):476-81. [DOI:10.1111/j.1742-7843.2011.00841.x]

[5] Mehrpoor O, Farzanezade H. Lead toxicity among oral opium addicts with abdominal pain: A case series of 17 cases. Indian Journal of Forensic Medicine \& Toxicology. 2017; 11(2):22-5. [DOI:10.5958/0973-9130.2017.00057.3]

[6] Kim H-C, Jang T-W, Chae H-J, Choi W-J, Ha M-N, Ye B-J, et al. Evaluation and management of lead exposure. Annals of Occupational and Environmental Medicine. 2015; 27(1):30. [DOI:10.1186/s40557-015-0085-9]

[7] Wani AL, Ara A, Usmani JA. Lead toxicity: A review. Interdisciplinary Toxicology. 2015; 8(2):55-64. [DOI:10.1515/ intox-2015-0009] 
This Page Intentionally Left Blank 